\title{
Pivotal Trials in Multiple Sclerosis: Similarities Prove Not to Be Useful
}

\author{
Carlo Avolio (1) · Diego Centonze
}

Received: September 24, 2021 / Accepted: October 8, 2021 / Published online: October 30, 2021

(c) The Author(s) 2021

\begin{abstract}
We present a commentary on the inclusion criteria and outcome measures of the major randomized trials on multiple sclerosis. A qualitative comparison of the characteristics of the enrolled patients is done. The objective is to stimulate a discussion about the need to improve research strategies. The discovery of new drugs studied without personalized criteria does not allow for useful advances in knowledge.
\end{abstract}

Keywords: Teriflunomide; Dimethyl fumarate; Fingolimod; Ocrelizumab; Diroximel fumarate;

C. Avolio

Department of Medical and Surgical Sciences,

University of Foggia, Foggia, Italy

C. Avolio $(\bowtie)$

Multiple Sclerosis Intradipartimental Center, Department of Neurosciences, Policlinico Riuniti,

Viale Luigi Pinto 1, 71100 Foggia, Italy

e-mail: carlo.avolio@unifg.it

D. Centonze

Multiple Sclerosis Research Unit, Department of Systems Medicine, Tor Vergata University, Rome, Italy

D. Centonze

Unit of Neurology and Neurorehabilitation, IRCCS Istituto Neurologico Mediterraneo (INM)

Neuromed, Pozzilli, Italy
Ozanimod; Ponesimod; Cladribine; Ofatumumab

\section{Key Summary Points}

Over the past 20 years, many diseasemodifying therapies have become accessible to patients with multiple sclerosis.

Pivotal trials are designed with the same inclusion criteria and outcome measures.

This commentary highlights that new drugs are being investigated on patients with similar prognostic characteristics.

Studying different drugs on very similar patients does not allow personalizing the therapies.

For the future, research on new therapies for multiple sclerosis that design clinical studies with precision medicine criteria is required.

\section{INTRODUCTION}

Multiple sclerosis (MS) is a neurodegenerative disease whose etiology is not yet fully 
understood [1]. Much evidence has accumulated over the past 30 years regarding the role of the immune system in MS [2]. This knowledge has opened the way to intense research on the role of modulation of the immune system. Today, many disease-modifying therapies (DMTs) are available for patients with MS [3]. In addition, in the last 2 decades, improvements obtained in terms of reduction of disease activity and quality of life are evident. Nevertheless, many questions remain unanswered. One of the open problems is the lack of staging for prognostic groups and the knowledge of predictive factors for the response to therapies [4]. Such uncertainties cause difficulties in offering patients an experimental therapy whose efficacy and safety are not known.

An indication of this difficulty is the strange similarity of the patients enrolled in the registration trials of recent years. The designed clinical studies with the same inclusion criteria have led to a mass of homogeneous data. This does not help in the choice of personalized therapies. In this article, we compare the basal characteristics of patients in different randomized studies to stimulate discussion on the need for precision medicine in the next few years.

For our qualitative analysis, we selected randomized pivotal studies conducted after 2000 . The main baseline characteristics of the randomized patients were compared in a synoptic table. For the qualitative analysis, only the experimental arms were selected at the dosages registered by the regulatory agencies. We use the teriflunomide TEMSO trial [5] as a reference value for the comparison tables.

\section{RESULTS AND DISCUSSION}

Fourteen randomized studies and nine molecules were screened for a qualitative comparison of the characteristics of the enrolled patients. Among the various studies, the median age values ranged from 34.5 to 41.9 years. The mean duration of disease was between 4.9 and 8.7 years. The median expanded disability status scale (EDSS) scores were very similar and always between 2 and 3 . Relapse rates in the year prior to randomization were identical.
Except for the EVOLVE MS-1 study, the percentage of patients with $\mathrm{Gd}+$ lesions was between 32 and 43\%. [5-16].

The diagnostic criteria for multiple sclerosis have undergone several updates over the past 2 decades. The aim was to improve the sensitivity to anticipate diagnosis and treatment and avoid irreversible disability progression. This diagnostic advance effort did not have an impact on clinical research. In fact, although the probability of correct diagnosis has improved, the inclusion criteria of the pivotal trails have remained the same. Despite advances in biomarker analysis and imaging technology, patients enrolled in randomized trials have strangely retained the same characteristics over the past 20 years. The TEMSO and CLARITY studies are among the oldest in this series. They show striking similarity in age and disease duration. Since then, even the trials conducted in the following years have shown an extraordinary similarity in basal characteristics (Table 1). An exception is the recent study on diroximel fumarate. The primary endpoint of this pivotal study was safety. The broader inclusion criteria made it possible to investigate patients up to 65 years with EDSS up to 6 [15]. Statistical dispersion measures reveal a tendency to enroll patients $<30$ years old and very rarely those $>50$ years. Certainly, the inclusion criterion of no later than 55 years is a restraint on the recruitment of patients $>50$ years (Table 2). Investigators probably find it too challenging or impractical to investigate new drugs in elderly patients or those with comorbidities. Furthermore, many patients $>50$ years old, even if eligible, meet the exclusion criteria because of the numerous pretreatments they have undergone. The repetitiveness of the median characteristics in the various studies analyzed coincides with the prevalence rates known to date for multiple sclerosis [17]. Therefore, the probability of offering an experimental therapy reflects the average population managed in clinical practice. The very large standard deviation values around age and disease duration suggest some effort by clinicians to enroll as many patients as possible. This trend is also confirmed by the high percentage of pretreated patients enrolled in the recent 


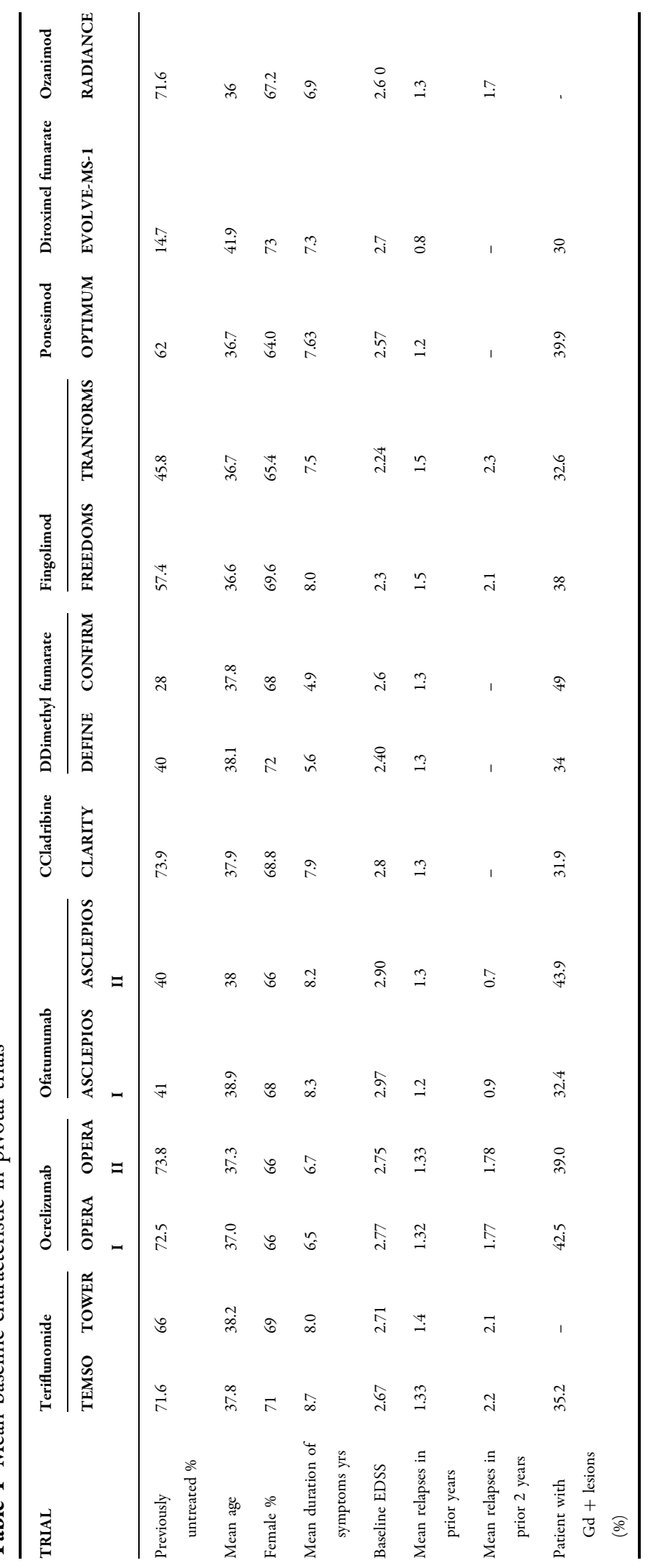




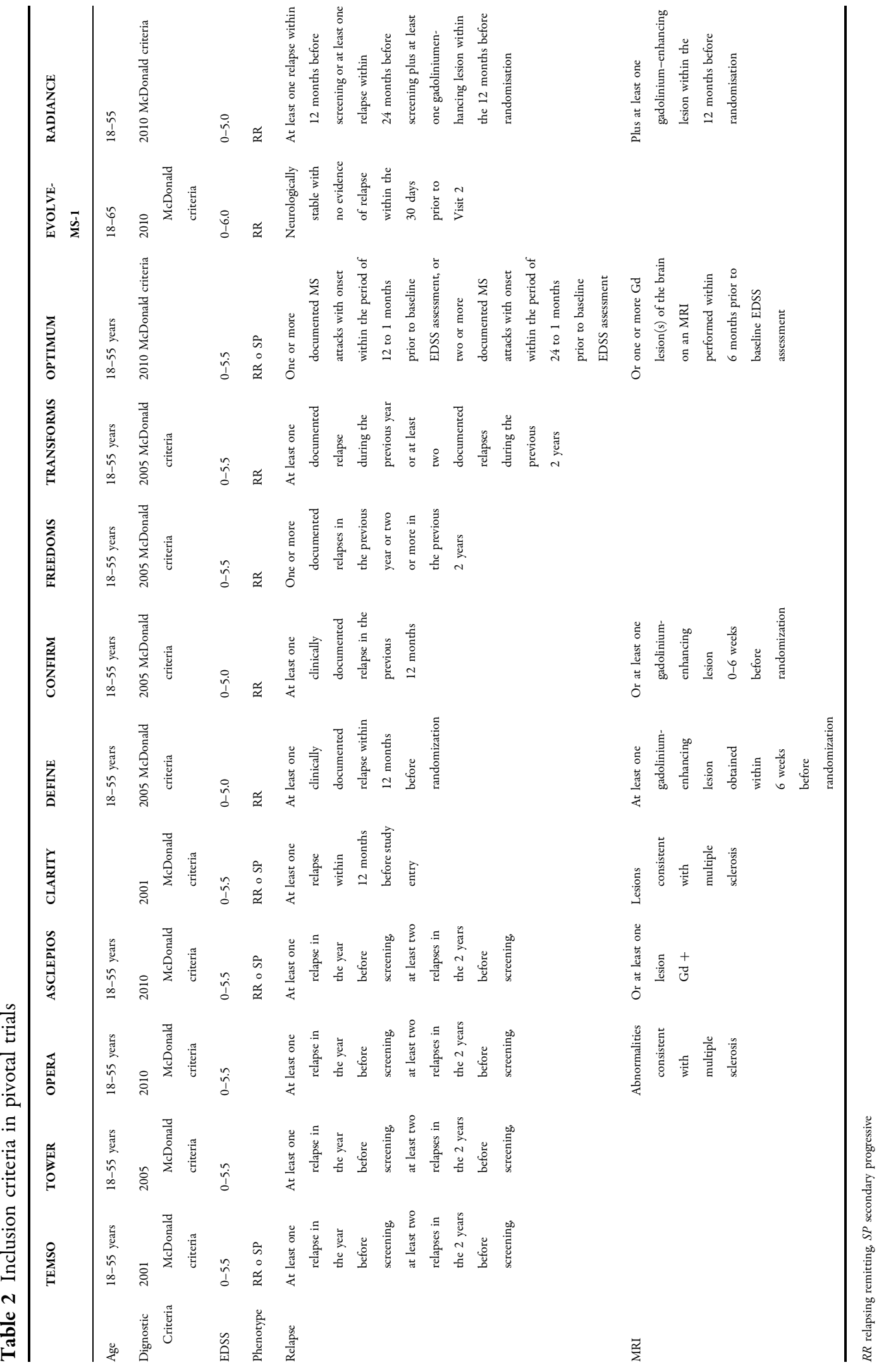


Table 3 Differences in the effect of teriflunomide in different trials

\begin{tabular}{lllll}
\hline Trial & Study drug & ARR & Comparator & ARR \\
\hline ASCLEPIOS I & Ofatumumab & 0.11 & Teriflunomide & 0.22 \\
ASCLEPIOS II & Ofatumumab & 0.10 & Teriflunomide & 0.25 \\
TEMSO & Teriflunomide & 0.37 & Placebo & 0.54 \\
TOWER & Teriflunomide & 0.32 & Placebo & 0.5 \\
\hline
\end{tabular}

$A R R$ annualized relapse rate

studies on ponesimod and diroximel fumarate. The presence of wider inclusion criteria does not demonstrate a change in median baseline characteristics. The CONFIRM, ASCLEPIOS and OPTIMUM studies allowed for randomization, even with only magnetic resonance activity, without relapse (Table 2). Nevertheless, the characteristics of the median patient were very similar to those of subjects in the other trials. Contrarily, the choice of more stringent inclusion criteria impacted the median characteristics of the enrolled patients at baseline. Eligible patients in the CARE-MS I study (alemtuzumab vs. interferon), aged 18-50 years, were only naïve to previous DMTs. They had a disease duration of up to 5 years and EDSS $\leq 3$. Here, the median patient is about 4 years younger than the in the other trials with a mean disease duration $<2$ years [18]. The AFFIRM study (natalizumab versus placebo) also showed a shift in the mean baseline characteristics of our series. Patients pretreated with interferon beta, glatiramer acetate or both for $>6$ months were excluded from randomization. Such criteria, in the absence of many therapeutic alternatives in 2001, may have prompted investigators to enroll naive patients with shorter disease duration [19]. The similarity of the basal characteristics of the patients enrolled in the different trials raises some questions. First, are we observing a random event or an involuntary selection bias caused by the preferences of clinicians and patients? Second, can we make adequate inferences from the sample to the patient universe about the effect of these treatments? Multiple sclerosis is a chronic disease that forces clinicians and patients to switch between DMTs. Having measured the effect of different DMTs with the same inclusion and exclusion criteria probably caused a homologation of the patient screening phases. The shared prudence in enrolling naive and very young or very old patients contributed to reducing the representativeness and variability of the sample. However, in clinical practice, these DMTs are used sequentially in the absence of sequence studies. Curiously, some recent pivotal trials chose teriflunomide as an active comparator. This does not allow an assessment of the differences in effect between drugs of the same class. Furthermore, it will be necessary to investigate the strong differences in the effect of teriflunomide on the same median patients in different trials (Table 3). The introduction of more precise inclusion criteria seems to have some impact on patient selection. In this case the price to pay could be a difficulty in enrollment, as evidenced by the lack of randomized trials in pediatric multiple sclerosis [20]. Furthermore, the power of data directness from the study to clinical practice would be reduced. Recently, the German MS Register, initiated by the Federal Association of the German Multiple Sclerosis Society, published an evaluation of the proportion of real-world patients fulfilling the inclusion and exclusion criteria of the phase III studies. Percentage of patients fulfilling all criteria of pivotal trials rarely exceeded 30\% [21]. This gap must stimulate a new way of conducting phase III studies. Therefore, pivotal studies should be designed with prognostically and not epidemiologically homogeneous criteria. Measuring the effect of new therapies on prognostically similar subsets would probably also allow for smaller sample sizes and faster results. 


\section{CONCLUSION}

To date, genetic research on alleles associated with multiple sclerosis susceptibility has not provided useful information for precision medicine. No biomarkers for the prognostic course of the disease have been validated [22]. Unfortunately, there are no known predictors of best response to treatment [23]. Over the past 20 years, great progress has been made in the diagnosis of multiple sclerosis. The awareness campaigns and multidisciplinary work have made it possible to anticipate diagnostics. Translational research is still very intense today. Several independent research groups have started pharmacogenomic investigations in multiple sclerosis [24]. The contributions of the pharmaceutical companies and the efforts of the regulatory agencies have greatly improved the expectation and quality of life in patients with multiple sclerosis. We suggest that future studies should investigate the effect of therapies more precisely. Comparing drugs with the same mechanism of action could be a useful step forward. Validating primary endpoints more consistent with drug action mechanisms will also be useful. CSF markers could be investigated in randomized trials as a primary endpoint in small samples. These and other suggestions coming from the scientific community will be the prerequisite for personalized medicine in the coming years.

\section{ACKNOWLEDGEMENTS}

Funding. No funding or sponsorship was received for this study or publication of this article. The journal's Rapid Service Fee was funded by the authors.

Authorship. All named authors meet the International Committee of Medical Journal Editors (ICMJE) criteria for authorship for this article, take responsibility for the integrity of the work as a whole and have given their approval for this version to be published.
Authors' Contributions. All authors (Carlo Avolio and Diego Centonze) contributed to the commentary writing, material preparation and data collection.

Disclosures. Carlo Avolio received honoraria for speaking, consultation fees and research grants from Biogen, Merck Serono, Novartis, Roche and Sanofi-Genzyme. He is an Advisory Board member of Biogen, Merck Serono, Novartis, Roche and Sanofi-Genzyme.

Diego Centonze is an Advisory Board member of Almirall, Bayer Schering, Biogen, GW Pharmaceuticals, Merck Serono, Novartis, Roche, Sanofi-Genzyme and Teva and received honoraria for speaking or consultation fees from Almirall, Bayer Schering, Biogen, GW Pharmaceuticals, Merck Serono, Novartis, Roche, Sanofi-Genzyme and Teva. He is also the principal investigator in clinical trials for Bayer Schering, Biogen, Merck Serono, Mitsubishi, Novartis, Roche, Sanofi-Genzyme and Teva. His preclinical and clinical research was supported by grants from Bayer Schering, Biogen Idec, Celgene, Merck Serono, Novartis, Roche, SanofiGenzyme and Teva.

Compliance with Ethics Guidelines. This article is based on previously conducted studies and does not contain any new studies with human participants or animals performed by any of the authors.

Data Availability. All data generated or analyzed during this study are included in this published article.

Open Access. This article is licensed under a Creative Commons Attribution-NonCommercial 4.0 International License, which permits any non-commercial use, sharing, adaptation, distribution and reproduction in any medium or format, as long as you give appropriate credit to the original author(s) and the source, provide a link to the Creative Commons licence, and indicate if changes were made. The images or other third party material in this article are included in the article's Creative Commons licence, unless indicated otherwise in a credit line to the material. If material is not included 
in the article's Creative Commons licence and your intended use is not permitted by statutory regulation or exceeds the permitted use, you will need to obtain permission directly from the copyright holder. To view a copy of this licence, visit http://creativecommons.org/licenses/by$\mathrm{nc} / 4.0 /$.

\section{REFERENCES}

1. Thompson AJ, Baranzini SE, Jeroen Geurts J, Hemmer B, Ciccarelli O. Multiple sclerosis. Lancet. 2018;391(10130):1622-36.

2. Baecher-Allan C, Kaskow BJ, Weiner HL. Multiple sclerosis: mechanisms and immunotherapy. Neuron. 2018;97(4):742-68.

3. Li H, Hu F, Zhang Y, Li K. Comparative efficacy and acceptability of disease-modifying therapies in patients with relapsing-remitting multiple sclerosis: a systematic review and network meta-analysis. J Neurol. 2020;267(12):3489-98.

4. Rotstein D, Montalban X. Reaching an evidencebased prognosis for personalized treatment of multiple sclerosis. Nat Rev Neurol. 2019;15(5): 287-300.

5. O'Connor P, Wolinsky JS, Confavreux C. Randomized trial of oral teriflunomide for relapsing multiple sclerosis. N Engl J Med. 2011;365(14):1293-303.

6. Confavreux C, O'Connor P, Comi G, et al. Oral teriflunomide for patients with relapsing multiple sclerosis (TOWER): a randomised, double-blind, placebo controlled, phase 3 trial. Lancet Neurol. 2014;13(3):247-56.

7. Hauser SL, Bar-Or A, Comi G, et al. Ocrelizumab versus interferon beta-1a in relapsing multiple sclerosis. N Engl J Med. 2017;376(3):221-34.

8. Hauser SL, Bar-Or A, Cohen JA, et al. Ofatumumab versus teriflunomide in multiple sclerosis. N Engl J Med. 2020;383(6):546-57.

9. Giovannoni G, Comi G, Cook S, et al. A placebocontrolled trial of oral cladribine for relapsing multiple sclerosis. N Engl J Med. 2010;362(5): 416-26.

10. Gold R, Kappos L, Arnold DL, et al. Placebo-controlled phase 3 study of oral BG-12 for relapsing multiple sclerosis. N Engl J Med. 2012;367(12): 1098-107.
11. Fox RJ, Miller DH, Phillips JT, et al. Placebo-controlled phase 3 study of oral BG-12 or glatiramer in multiple sclerosis. N Engl J Med. 2012;367(12): 1087-97.

12. Kappos L, Radue EW, O'Connor P, et al. A placebocontrolled trial of oral fingolimod in relapsing multiple sclerosis. N Engl J Med. 2010;362(5): 387-401.

13. Cohen JA, Barkhof F, Comi G, et al. Oral fingolimod or intramuscular interferon for relapsing multiple sclerosis. N Engl J Med. 2010;362(5):402-15.

14. Kappos L, Fox RJ, Burcklen M, et al. Ponesimod compared with teriflunomide in patients with relapsing multiple sclerosis in the active-comparator phase 3 OPTIMUM study: a randomized clinical trial. JAMA Neurol. 2021;78(5):558-67.

15. Naismith RT, Wolinsky JS, Wundes A, et al. Diroximel fumarate (DRF) in patients with relapsing-remitting multiple sclerosis: interim safety and efficacy results from the phase 3 EVOLVE-MS-1 study. Mult Scler J. 2020;26(13):1729-39.

16. Cohen JA, Comi G, Selmaj KW, et al. Safety and efficacy of ozanimod versus interferon beta-1a in relapsing multiple sclerosis (RADIANCE): a multicentre, randomised, 24-month, phase 3 trial. Lancet Neurol. 2019;18(11):1021-33.

17. Wallin MT, Culpepper WJ, Nichols E, Bhutta ZA, Gebrehiwot TT, Hay SI, Khalil IA, Krohn KJ, Liang $\mathrm{X}$, Naghavi M, Mokdad AH. Global, regional, and national burden of multiple sclerosis 1990-2016: a systematic analysis for the global burden of disease study 2016. Lancet Neurol. 2019;18(3):269-85.

18. Cohen JA, Coles AJ, Arnold DL, et al. Alemtuzumab versus interferon beta $1 \mathrm{a}$ as fi rst-line treatment for patients with relapsing-remitting multiple sclerosis: a randomized controlled phase 3 trial. Lancet. 2012;380(9856):1819-28.

19. Polman $\mathrm{CH}, \mathrm{O}^{\prime}$ Connor PW, Havrdova E, et al. A randomized, placebo-controlled trial of natalizumab for relapsing multiple sclerosis. N Engl J Med. 2006;354(9):899-910.

20. Chitnis T, Arnold DL, Brenda Banwell B, et al. Trial of fingolimod versus interferon beta- $1 \mathrm{a}$ in pediatric multiple sclerosis. N Engl J Med. 2018;379:1017-27.

21. Jalusic KO, Ellenberger D, Rommer P, Stahmann A, Zettl U, Berger K. Effect of applying inclusion and exclusion criteria of phase III clinical trials to multiple sclerosis patients in routine clinical care. Mult Scler. 2021. https://doi.org/10.1177/ 1352458520985118 . 
22. George MF, Briggs FB, Shao X, et al. Multiple sclerosis risk loci and disease severity in 7,125 individuals from 10 studies. Neurol Genet. 2016;2(4):e87.

23. Chitnis T, Prat A. A roadmap to precision medicine for multiple sclerosis. Mult Scler. 2020;26(5): 522-32.
24. Tsarevaa E, Kulakovaa O, Boykob A, Favorova O. Pharmacogenetics of multiple sclerosis: personalized therapy with immunomodulatory drugs. Pharmacogenet Genomics. 2016;26(3):103-15. 